\title{
Boombestuurskundetijdschriften
}

\section{TTIP tentatief in lokaal perspectief}

Prof. mr. dr. Helen Stout

\begin{abstract}
Aanbevolen citeerwijze bij dit artikel
Prof. mr. dr. Helen Stout, 'TTIP tentatief in lokaal perspectief', $B W$ 2017-1, p. $54-66$
\end{abstract}

Vorigjaar hebben de eerste Nederlandse gemeenten zichzelf TTIP-vrij verklaard en de lijst groeit. De teller staat nu op 27 gemeenten, 3 provincies en 2 waterschappen. TTIP zorgt ervoor dat buitenlandse bedrijven erop kunnen vertrouwen dat investeringen in een gastland gepleegd, veilig zijn en niet zomaar kunnen worden weggenomen of teniet worden gedaan. Maar wat als investeringen op gespannen voet staan of komen te staan met maatregelen die een overheid bijvoorbeeld uit het oogpunt van bescherming van het milieu heeft genomen of voornemens is te nemen? Heeft een overheid die vrijheid onder TTIP nog? Of alleen wanneer zij bereid is diep in de buidel te tasten? Vergelijkbare praktijken laten zien dat het niet om kinderachtige bedragen gaat. Wat kunnen we van TTIP in dit opzicht verwachten? De vraag die in dit essay centraal staat, is of, en zo ja, in hoeverre de investeringsbescherming die TTIP biedt in combinatie met de in het verdrag voorziene arbitrage decentrale overheden belemmert bij het nemen van beslissingen in het algemeen belang.

\section{Inleiding}

In naburige landen als België, Duitsland en Oostenrijk maken ze zich al langer zorgen over het Trans-Atlantisch Vrijhandels- en Investeringsverdrag (Transatlantic Trade and Investment Partnership, afgekort tot: TTIP) en de gevolgen van dit handelsverdrag voor decentrale overheden. In Nederland leek men zich tot voor kort niet of nauwelijks te interesseren voor het vrijhandelsverdrag, dat nog niet is getekend en waarover de onderhandelingen nog in volle gang zijn. Gemeentebestuurders konden zich niet druk maken om handelsstromen, importtarieven, intellectueel eigendomsrecht van producten uit andere 
vanwege geruchten over torenhoge schadevergoedingen die via arbitrage in het kader van investeringsbescherming kunnen worden afgedwongen van overheden die gewoon hun wettelijke taken uitvoeren. Zal TTIP de armslag van overheden verkleinen waar het gaat om het nemen van beslissingen of het treffen van maatregelen die vanuit het algemeen belang bezien wenselijk en nodig zijn, maar door buitenlandse bedrijven gepleegde investeringen negatief beïnvloeden? In 2015 heeft de Europese koepelvereniging van gemeenten (Council of European Municipalities and Regions) zich kritisch over TTIP uitgelaten en uitgesproken dat het verdrag nooit en te nimmer gemeenten mag belemmeren bij het vervullen van wettelijke taken en uitoefenen van bevoegdheden in het algemeen belang. Vorig jaar hebben de eerste Nederlandse gemeenten zichzelf TTIP-vrij verklaard en de lijst groeit (VNG, 2015). De teller staat nu op 27 gemeenten, 3 provincies en 2 waterschappen. ${ }^{\mathbf{1}}$ In Europa zijn al

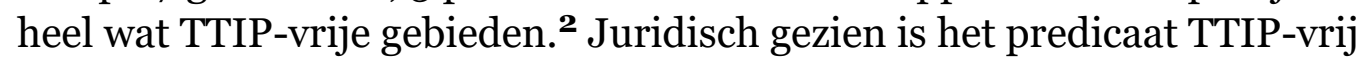
weliswaar onzinnig (immers, het predicaat is juridisch volslagen irrelevant), maar het heeft zeker kracht qua (politieke) symboliek. Is de angst voor omvangrijke schadevergoedingen door TTIP terecht? Wat kunnen we van TTIP in dit opzicht verwachten?

De vraag die in dit essay centraal staat, is of, en zo ja, in hoeverre de investeringsbescherming die TTIP biedt in combinatie met de in het verdrag voorziene arbitrage, decentrale overheden belemmert bij het nemen van beslissingen in het algemeen belang. Aangezien over de praktijk van TTIP nog niets bekend is - het verdrag zit immers nog in de pijplijn - passen we de kunstgreep van de analogie toe. Er bestaan al een aantal handelsverdragen met een vergelijkbaar doel en een vergelijkbare strekking, die bovendien in redactie wat de specifieke verdragsbepalingen betreft overeenstemmen met TTIP. Bij deze verdragen heeft zich al een uitgebreide geschillenbeslechtingspraktijk ontsponnen, waarnaar we kunnen kijken. Aan de hand van twee geschillen tussen decentrale overheden en buitenlandse investeerders betogen wij in dit essay dat TTIP reële financiële risico's bevat voor decentrale overheden die in een afweging het algemeen belang laten prevaleren boven het individuele belang van de buitenlandse investeerder. Waar de Nederlandse rechter overheidsorganen de benodigde beleidsmatige armslag laat, doen arbiters, die vooral de investeerders beschermen, dit niet of veel minder.

\section{Nieuwe generatie handelsverdragen}

TTIP komt niet uit de lucht vallen. Het volkenrecht kent van oudsher handelsverdragen die zijn gericht op het bevorderen van internationale economische groei door handelsbarrières tussen staten weg te nemen (Horbach e.a., 2007). Te denken valt daarbij aan invoerrechten, handelsquota en exportheffingen, traditioneel belangrijke obstakels voor vrije handel. TTIP behoort tot een nieuwe generatie handelsakkoorden en vormt als het ware een vervolg op de oude afspraken over het uitbannen van douanerechten. Deze nieuwe generatie verdragen gaat verder en is gericht op het creëren van een gunstig internationaal 
tussen bestaande rechtssystemen te verkleinen door wetten en regels op elkaar af te stemmen.

Investeringsbescherming wordt tegenwoordig onontbeerlijk geacht voor een gunstig internationaal investeringsklimaat. Het gaat er dan om dat buitenlandse bedrijven erop kunnen vertrouwen dat investeringen in een gastland gepleegd, veilig zijn en niet zomaar kunnen worden weggenomen of teniet worden gedaan. De mogelijkheid een geschil met een staat voor te leggen aan een arbiter vormt het sluitstuk van de investeringsbescherming. Investor State Dispute Settlement ofwel ISDS is een veelvoorkomende vorm van arbitrage in het internationaal investeringsrecht (Newcombe \& Paradell, 2009; Tietje \& Baetens, 2014; Italaw). Bij ISDS ligt de beslechting van investeringsgeschillen in handen van ad hoc arbiters, die door partijen worden gekozen en op basis van een commercieel uur- of dagtarief onder strikte geheimhouding werken. De oorsprong van ISDS moet worden gezocht in de behoefte aan een alternatieve rechtsgang, met name in landen die worden geteisterd door corruptie en nepotisme en niet over onafhankelijke rechtspraak beschikken.

Evenzeer als investeringsbescherming is afstemming van wet- en regelgeving een belangrijk oogmerk van de nieuwe verdragen. De ervaring heeft namelijk geleerd dat het moderne economische verkeer vooral ook hinder ondervindt van de eisen die aan producenten en producten worden gesteld, die per land verschillen. Wanneer een Europese producent bijvoorbeeld een auto op de Amerikaanse markt wil brengen, moet de wagen aan twee verschillende standaarden voldoen. Om die reden kennen de nieuwe verdragen bepalingen om wetten en regels van de verdragsluitende staten zoveel mogelijk op één lijn te brengen. Bestaande obstakels voor handel kunnen zo eenvoudig worden weggenomen en toekomstige mogelijk voorkomen.

De nieuwe generatie verdragen roept nieuwe vragen op. Hoe ver moet de bescherming van buitenlandse investeerders gaan, bijvoorbeeld wanneer een arm land voortaan de eigen, rijke bodemschatten wil exploiteren juist om aan de bestaande armoede een einde te maken? En als het doel is om de verschillen in regelingen, standaarden en procedures waarmee bedrijven die producten op een buitenlandse markt willen brengen, te maken hebben, weg te nemen, wiens regelingen, standaarden en procedures zijn dan leidend? Europa bijvoorbeeld kent vanouds een hoog beschermingsniveau op het gebied van arbeid, milieu, gezondheid en veiligheid, maar dat geldt niet voor staten elders in de wereld. De economische en culturele verschillen tussen landen kunnen groot zijn. Amerikanen denken bijvoorbeeld heel anders dan Nederlanders over het gebruik van proefdieren in de cosmetica-industrie of over genetisch gemodificeerde gewassen. Het kleinere zusje van TTIP, CETA (Comprehensive Economic and Trade Agreement), het handelsverdrag met Canada, dat een vergelijkbare inhoud heeft en al eerder in voorbereiding was, heeft om die reden, tot het laatste moment toe, verzet ondervonden van het Waalse regioparlement. 
We kennen op dit moment een grote hoeveelheid bilaterale handelsverdragen nieuwe stijl onder verschillende benamingen zoals BITs (Bilateral Investment Treaties), IIAs (International Investment Agreements) en FTAs (Free Trade Agreements). Om een indruk te geven van de omvang: de EU-lidstaten hebben er samen meer dan 1000. De afgelopen jaren zijn daar een aantal grote, multilaterale handelsverdragen bij gekomen. Denk bijvoorbeeld aan NAFTA (North American Free Trade Agreement), een verdrag uit 1994 dat een vrijhandelszone vestigt tussen Canada, de VS en Mexico. Of aan ECT (Energy Charter Treaty), een handelsovereenkomst van de energiebranche uit 1991 die door meer dan 50 staten en de EU is ondertekend.

\section{TIP-Leaks}

De meest recente loot aan de stam van de nieuwe generatie handelsverdragen is TTIP, een verdrag tussen de EU en de VS. Heel veel bekend over TTIP is er niet. De onderhandelingen, die al jaren aan de gang zijn, verlopen in het geheim. Af en toe lekken afspraken die de onderhandelaars hebben gemaakt naar de pers, maar dat is het dan. Greenpeace heeft kortgeleden alle beschikbare tekstvoorstellen online gezet. $^{\mathbf{3}}$ Hoewel het een niet-geautoriseerde tekst betreft, geeft het wel een indruk van de onderwerpen waarover in de achterkamertjes is gepraat en in welke richting de onderhandelaars denken waar het de oplossing van zich voordoende knelpunten betreft. De omvang van het verdrag is indrukwekkend. Het verdrag bevat een enorme hoeveelheid bepalingen, in de online variant zo'n slordige 200, en bestrijkt veel beleidsterreinen (landbouw, telecom, voedsel, verkeer en vervoer, enz.).

\section{TTIP onder vuur}

Onder aanvoering van grote belangenorganisaties levert Nederland slag tegen TTIP. De belangrijkste argumenten die tegen TTIP worden aangevoerd, zijn - kort samengevat - dat het verdrag waarden op het gebied van milieu, voedselveiligheid en dierenwelzijn verkwanselt en dat het tegen de waarden van de democratische rechtsstaat indruist (zie o.a. Meuwese, 2016).

Critici zijn bang dat de verplichting tot afstemming van de regelgeving aan beide zijden van de Atlantische Oceaan, tot een algemene versoepeling van eisen op het gebied van milieu, voedselveiligheid en dierenwelzijn zal leiden. Met TTIP zouden de strengere Europese voorschriften kunnen worden ingeruild voor de lichte Amerikaanse. Denk bijvoorbeeld aan het in de EU gebruikelijke principe dat alleen producten op de markt mogen worden gebracht die bewezen veilig zijn. Dat zou kunnen worden vervangen door de in de VS gebruikelijke benadering dat zolang de schadelijkheid van een product niet is bewezen, het product gewoon mag worden verkocht. Nog een ander voorbeeld. De VS kennen nauwelijks dierenwelzijnswetten. De omstandigheden waarin productiedieren daar leven, zijn ronduit slecht te noemen. Het zou zo 
staan. Het Amerikaanse vlees, dat door TTIP eenvoudig in de koelvitrines van de Europese supermarkten kan belanden, zou zó goedkoop kunnen zijn dat Europese voedselproducenten zich gedwongen zouden kunnen voelen om te beknibbelen op dierenwelzijn en tot een verlaging van de standaarden over te gaan. Dit mogelijke probleem heeft een belangrijke rol gespeeld bij de weigerachtigheid van de Walen om CETA te ondertekenen. Zij vrezen dat CETA de Europese normen op het gebied van arbeid, milieu en landbouw zal ondergraven en eisen extra garanties dat dit niet zal gebeuren.

De democratische rechtsstaat komt volgens critici op een aantal punten onder druk te staan. Ten eerste door de wijze van totstandkoming van het verdrag (a). Ten tweede doordat buitenlandse investeerders in staat worden gesteld overheden aan te klagen als deze in het algemeen belang maatregelen doorvoeren die de bedrijfsresultaten kunnen schaden (b). Ten derde door het ontstaan van parallelle rechtssystemen en -gangen: specifieke investeringsbescherming en arbitrage voor de buitenlandse investeerders en gewone regels en gewone rechtspraak voor alle anderen (c). Ten vierde door regulatory cooperation, doordat niet alleen afspraken worden gemaakt over bestaande regels, maar ook over het afstemmen van toekomstige wet- en regelgeving (d). In het hiernavolgende worden de vier kritiekpunten a, b, c en d besproken.

\section{a. Geheime onderhandelingen}

De onderhandelingen over TTIP worden gevoerd door ambtenaren achter gesloten deuren, die voor grote industrielobby's wel op een kier zouden staan. Doordat strikte geheimhouding wordt betracht en geen enkel (onderliggend) document of vergaderstuk in de openbaarheid verschijnt, is een brede maatschappelijke discussie nauwelijks mogelijk, wat gegeven de omvang van het verdrag alsmede de ingrijpende sociale en economische gevolgen ervan, wél wenselijk is met het oog op een evenredige belangenafweging. Aangezien de normale mechanismen van 'checks and balances' niet (kunnen) functioneren, zou het gevaar van eenzijdige belangenarticulatie kunnen ontstaan.

\section{b. Klachtrecht}

In het voorstel voor een regeling van investeringsbescherming dat de Europese Commissie in 2014 naar buiten bracht, stond ISDS centraal. Bij ISDS krijgen bedrijven het recht om een staat bij een arbitragecommissie aan te klagen wanneer één van zijn organen een maatregel neemt ten gevolge waarvan verwachte economische rendementen van een gepleegde investering uitblijven of teniet worden gedaan. Volgens critici draagt ISDS het gevaar in zich dat buitenlandse investeerders invloed uitoefenen op de, met democratische waarborgen omklede, publieke besluitvorming. Sommigen waarschuwen voor 'regulatory chill', het verschijnsel waarbij bestaande regelgeving onder druk van (de dreiging van) claims wordt afgezwakt of regelgeving die de overheid voornemens is uit te vaardigen om diezelfde reden in de iiskast wordt gezet. Immers, 
buitenlandse investeerder ontstaat en de kans op betaling van aanzienlijke geldsommen aan schadevergoeding aanwezig is.

\section{c. Twee soorten recht(spraak)}

Met het klachtrecht voor buitenlandse bedrijven ontstaat er een apart rechtsstelsel naast het bestaande rechtssysteem en een aparte rechtsgang naast de gewone rechtsgangen. Daarmee wordt het bestaande rechtssysteem doorkruist. Bovendien kan er rechtsongelijkheid ontstaan. Daar waar de buitenlandse investeerder zijn rechten, ontleend aan het internationaal investeringsrecht, onverkort tot uitdrukking kan brengen voor een arbiter, is een binnenlandse investeerder gehouden aan de gewone regels van het recht alsmede tot het volgen van de normale gerechtelijke procedures. Het gewone recht biedt de binnenlandse investeerder geen extra bescherming. De verschillen tussen de twee rechtsgangen zijn enorm. Niet alleen wat betreft processuele waarborgen die bij arbitrage nagenoeg afwezig zijn, zoals garanties voor onafhankelijkheid en onpartijdigheid van de rechter en openbaarheid van de zitting, maar ook wat betreft de (omvang van de) toetsing.

De gewone rechter is gehouden het recht toe te passen. Hij moet zich rekenschap geven van het volledige corpus iuris. Laten we het er gemakshalve maar op houden dat artikel 79 van de Wet op de rechterlijke organisatie - hoewel veel complexer - dat bepaalt. De activiteit van de rechter die in een procedure om een oordeel wordt gevraagd, de rechtsvinding, bestaat eruit om uit de verschillende rechtsbronnen (nationale en internationale rechtsregels, geschreven en ongeschreven rechtsbeginselen, regels afkomstig van de centrale overheid en gemeentelijke of provinciale regelgeving e.d.) het van toepassing zijnde recht te selecteren en naar de bestaande situatie te concretiseren aan de hand van een belangenafweging. Wanneer een overheidsmaatregel ter toetsing aan de gewone rechter wordt voorgelegd zal deze naar vaste jurisprudentie tot een belangenafweging komen waarbij een zwaar gewicht wordt toegekend aan publieke belangen, zeker wanneer deze zijn geborgd in wet- en regelgeving.

Arbiters spreken geen 'recht' zoals gewone rechters doen, maar doen aan geschillenbeslechting in een specifieke en beperkte context. Bij internationale investeringsarbitrage zijn de verdragsbepalingen met betrekking tot de investeringsbescherming leidend. Die zijn eenzijdig en exclusief gericht op de rechten van investeerders. De arbiters zijn niet gebonden aan de rechtsregels die gelden voor iedere persoon die zich op het grondgebied van de staat bevindt, bijvoorbeeld ten aanzien van milieu of gezondheid. Zo beschouwd hebben arbiters een afgebakende focus en geven zij zich geen rekenschap van het geldende recht binnen een bepaalde staat. Theoretisch zou een arbiter tot een oordeel kunnen komen, dat, zou het oordeel afkomstig zijn geweest van een echte rechter, dit door de Hoge Raad wegens schending van het 'recht' op grond van artikel 79 van de Wet op de rechterlijke organisatie moet worden gecasseerd (lees: vernietigd). De arbiter pleegt dus een veel 
schadevergoeding voor een gewone rechter, nog daargelaten de aspecten van wat als 'schade' wordt beschouwd alsmede de berekening van de vergoeding.

\section{d. Regulatory cooperation}

TTIP wil niet alleen bestaande wetten en regels op één lijn brengen. De ambitie beslaat ook de toekomst: de onderhandelaars willen voorkomen dat er in de toekomst nieuwe handelsbarrières als gevolg van wet- en regelgeving ontstaan. In de huidige voorstellen is daarom voorzien in de oprichting van een 'Regulatory Cooperation Body', een ambtelijke orgaan dat tot taak heeft negatieve effecten van wet- en regelgeving op transAtlantische handel en investeringen te voorkomen, door al in het ontwerpstadium bij een verdragsstaat aan de bel te trekken. Hieraan kleeft een belangrijk bezwaar waar het de democratische kwaliteit van wet- en regelgeving betreft. Want hoewel er formeel gezien niets aan de bestaande wetgevingsprocedures verandert, zou een verschuiving van macht en invloed kunnen plaatsvinden naar de informele kaders waarbinnen een dergelijk orgaan opereert. Door de informatie- en kennisvoorsprong van het orgaan zou het de ruimte kunnen krijgen om buiten of zelfs tegen het belang van de nationale of supranationale wetgever het 'eigen belang' te dienen. Gegeven de grote invloed van de Amerikaanse bedrijvenlobby in Brussel is het niet ondenkbeeldig dat regulatory cooperation, hoewel op de tekentafel transparant en democratisch geborgd, in de greep van enkelen geraakt.

\section{ISDS in de prullenmand}

Door alle kritiek heeft ISDS het niet gehaald. De Europese Commissie moest bakzeil halen. Investment Court System (ICS) is het nieuwe systeem van geschillenbeslechting dat nu als voorstel voorligt. ${ }^{\mathbf{4}}$ Met ICS, waarin een aantal elementen uit de gewone rechtspraak zijn opgenomen, beoogt de Europese Commissie bezwaren van ISDS te ondervangen. Waarborgen voor onafhankelijkheid en onpartijdigheid meent de Commissie te kunnen creëren door openbaarheid van de zittingen voor te schrijven, alsmede door benoemingseisen te stellen aan arbiters, die bovendien op een soort basisbezoldiging kunnen rekenen. De beslissingen van het tribunaal zijn onderworpen aan een hoger beroep, waardoor eventuele fouten die in eerste aanleg zijn gemaakt, kunnen worden gecorrigeerd en tevens consistentie in beslislijn kan worden verkregen.

Het nieuwe voorstel van de Europese Commissie vindt in de ogen van critici evenmin genade. Kort samengevat komt de kritiek op het volgende neer. Evenals bij ISDS zijn de 'rechters' bij ICS wat hun inkomsten betreft grotendeels afhankelijk van het aantal procesdagen dat ze maken, waardoor hun onafhankelijkheid onder druk kan komen te staan.

Immers, alleen buitenlandse investeerders kunnen een zaak aanspannen, waardoor de neiging bij de 'rechters' zou kunnen ontstaan om een zekere gewilligheid ten toon te spreiden ten opzichte van investeerdersbelangen. 
wordt beslecht of tot een schikking leidt. 5 Deze cijfers zouden hiervoor mogelijk een aanwijzing kunnen zijn. Het grootste bezwaar tegen ISDS blijft bij ICS bestaan: doorkruising van het rechtssysteem, apart recht voor buitenlandse investeerders en een aparte rechtsingang. Evenals ISDS is ICS, anders dan de term suggereert, een vorm van arbitrage, private rechtspraak.

\section{Investeringsbescherming in TTIP: vergelijkbare praktijken}

In artikel 5, eerste lid (opgenomen in Chapter II, 'Investment' als onderdeel van de 'Title on trade in services, investment and ecommerce') is het een staat verboden om een buitenlandse investering direct of indirect (d.w.z. met een effect gelijk aan onteigening) te onteigenen. Dit artikel komt woordelijk overeen met de betrokken bepalingen uit NAFTA en ECT. Vanwege de tekstuele overeenkomst met deze handelsverdragen kan op goede gronden worden aangenomen dat de geschillenbeslechtingspraktijk die zich bij NAFTA en ECT heeft ontsponnen, tevens van belang is voor TTIP, in welk opzicht zij een voorspellende waarde kan hebben. In het navolgende bekijken we de wijze waarop geschillen onder vigeur van NAFTA en ECT worden beslecht. Dat doen we aan de hand van twee zaken waarin een decentrale overheid die een beslissing in het algemeen belang heeft genomen, tegenover een buitenlandse investeerder is komen te staan: de bouw van de kolencentrale in Hamburg en de intrekking van de winningsvergunning voor schaliegas door de Canadese provincie Quebec. De kwestie die in beide gevallen aan de orde is, is de vraag naar de reikwijdte van de investeringsbescherming.

\section{Kolencentrale Hamburg}

In 2007 startte de Zweedse energiereus Vattenfall met de bouw van een grote elektriciteitscentrale in de Hamburgse wijk Moorburg. De nieuwe kolengestookte centrale, die naar schatting 2,6 miljard euro heeft gekost, was van het begin af aan zwaar omstreden. $\mathrm{Al}$ in 2005, toen de eerste plannen voor de bouw van de centrale naar buiten werden gebracht, laaiden protesten op vanwege de negatieve gevolgen voor de leefomgeving. Inwoners van Hamburg vreesden de enorme luchtverontreiniging die met de verbranding van steenkolen gepaard zou gaan. Milieuorganisaties zagen met de mega-centrale, die jaarlijks vele tonnen $\mathrm{CO}_{2}$ zou uitspuwen, de klimaatdoelstellingen ernstig in gevaar komen. In 2007 hebben tegenstanders van de centrale nog getracht de bouw ervan tegen te houden met een volkspetitie, maar tevergeefs. De installatie werd op 18 november 2015 volledig in gebruik genomen, drie jaar later dan oorspronkelijk gepland. Met een bruto capaciteit van 1654 megawatt aan elektriciteit en 650 megawatt aan warmte-krachtkoppeling behoort de centrale van Moorburg tot een van de grootste van Europa.

Op 30 september 2008 verleende de Behörde für Stadtentwicklung und Umwelt (BSU), de bevoegde instantie van de gemeente Hamburg, een 
werd ter bescherming van het aquatisch milieu de hoeveelheid koelwater die op een bepaald moment mocht worden ingenomen c.q. geloosd, afhankelijk gesteld van de hoogte van het waterpeil alsmede van de temperatuur en het zuurstofgehalte van de rivier. Een vistrap moest ervoor zorgen dat naar de stroomopwaarts gelegen Natura 2000gebieden migrerende vissen niet met het ingenomen koelwater meegezogen zouden worden en de dood vinden. Om ook in droge, hete zomers, wanneer de waterstand in de rivier laag is, de centrale in werking te houden was een koeltoren aangewezen. De bouw van een koeltoren en de aanleg van een vistrap zouden het Zweedse bedrijf veel geld kosten, naar schatting zo'n 600 miljoen extra. Na bij de bestuursrechter, het Hamburgse Oberverwaltungsgericht, de vergunning te hebben aangevochten en in het ongelijk te zijn gesteld, heeft Vattenfall in april 2009 gebruikgemaakt van de mogelijkheid tot arbitrage die ECT biedt. Volgens het energieconcern tast de strenge vergunning de winstgevendheid van de in aanbouw zijnde centrale aan. Bij de staat Duitsland werd een schadeclaim van 1,4 miljard dollar neergelegd (die in geval van verlies door de staat aan Hamburg zou worden doorberekend). De procedure verliep in het geheim. Het kwam niet tot een uitspraak doordat partijen in augustus 2010 een schikking troffen. Het bedrag van de schikking is geheim. Wel meldde het Duitse Handelsblatt op 2 november 2011 dat de uitkomst voor Vattenfall volgens een woordvoerder 'geheel bevredigend' is.

\section{Schaliegas Quebec}

Het Amerikaanse olie- en gasconcern Lone Pine Resources Inc. heeft in de periode tussen 2006 en 2011 een aantal vergunningen aangevraagd en gekregen voor het opsporen en winnen van gas en olie op verschillende plaatsen in de provincie Quebec. Een van deze plaatsen betreft de bodem onder de Sint Laurens rivier, waarin zich grote voorraden schaliegas bevinden, die Lone Pine eruit wil halen. De Sint Laurens rivier is met een lengte van $1140 \mathrm{~km}$ een van de langste rivieren van Canada. Het verbindt de omvangrijke meren van Canada met elkaar en is ecologisch van grote betekenis. De rivier ontspringt bij Lake Ontario en mondt met een breed estuarium uit in de Atlantische Oceaan. Dit estuarium is vermaard als ontmoetingsplaats van walvissen.

Aan de winning van schaliegas zijn belangrijke risico's voor het milieu verbonden. Schaliegas zit diep in de aarde, in de poriën van ondergrondse steenlagen. Om schaliegas uit de bodem te kunnen halen moet een speciale techniek worden toegepast, 'hydraulic fracturing', waarbij onder grote druk een mengsel van water, zand en chemicaliën in de bodemlaag wordt geïnjecteerd. Deze techniek, ook wel 'fracken' genoemd, is niet zonder risico. Bij elke boring wordt er een of meer keren 'gefrackt'. Per frack gaan miljoenen liters chemisch verontreinigd water de bodem in, die vervolgens weer naar boven worden gezogen samen met - en daar is het allemaal om begonnen - opgeloste belletjes schaliegas. $\mathrm{Na}$ afvang van het gas blijft hoog verontreinigd frackwater over dat niet zelden weer terug in de bodem wordt genomnt. F.r kan bij fracking dien 
verontreiniging van bodem, grondwater, natuur en landbouwgrond tot gevolg hebben. Zou een dergelijke verontreiniging plaatsvinden, dan zijn er geen remedies. De enige effectieve reinigingsmethode is afgraven, maar dat is alleen tot een bepaalde diepte haalbaar. Bij het fracken zelf ontstaan seismisch waarneembare schokgolven, waardoor de boortunnel kan worden beschadigd en chemicaliën in de bodem kunnen weglekken. Ook bestaat het risico dat frackvloeistof in reeds bestaande breuken in de ondergrond terechtkomt. Deze breuken kunnen in beweging komen en (zware) aardbevingen tot gevolg hebben. Daarnaast bestaan bij de schaliegaswinning de 'gewone' risico's van inklinking en bodemdaling die zich ook bij aardgaswinning kunnen voordoen.

Onder grote politieke druk startte de regering van Quebec in 2010 een brede maatschappelijke discussie over schaliegaswinning onder leiding van Bureau d'audiences publiques sur l'environment (BAPE). Op basis van de aanbevelingen van BAPE kondigde de minister van natuurlijke hulpbronnen op 9 november 2010 een moratorium af, waardoor alle activiteiten met betrekking tot schaliegas in de Sint Laurens rivier moesten worden gestaakt, ook die waarvoor aan Lone Pine eerder vergunning was verleend. Op 12 mei 2011 heeft de regering van de provincie Quebec een wetsvoorstel ingediend inhoudende de intrekking van alle vergunningen betreffende mijnbouwactiviteiten in de Sint Laurens rivier zonder schadeloosstelling van de vergunninghouders. Blijkens de toelichting beoogt het voorstel de bescherming van mens en milieu tegen de mogelijk schadelijke gevolgen van schaliegaswinning. Het voorstel kreeg kracht van wet op 13 juni 2011. De provincie van Quebec heeft eigen wetgevende bevoegdheden. Canada is een federatie, bestaande uit tien, in hoge mate autonome, provincies die elk over een eigen regering en parlement beschikken. Binnen het grondwettelijk kader zijn de Canadese provincies soeverein en beschikken zij over eigen jurisdictie, waar de federale regering geen zeggenschap over heeft.

Lone Pine liet het er niet bij zitten. Het bedrijf diende op 8 november 2012 een klacht in tegen de staat Canada wegens schending van de rechten die Lone Pine als buitenlandse investeerder op basis van NAFTA toekwam. De schadeclaim bedraagt 118,9 miljoen dollar. Canada verweert zich door te wijzen op zijn rechten als staat om naar eigen inzicht wetten in het algemeen belang vast te stellen. Wetgeving betreft een legitieme uitoefening van de bevoegdheden van een soevereine staat en kan om die reden nooit onrechtmatig zijn. Het arbitragetribunaal waaraan de zaak is voorgelegd, heeft nog geen beslissing genomen.

\section{Sole effect- versus police power-doctrine}

De twee zaken en het verloop ervan laten zich goed begrijpen wanneer we iets dieper het internationaal investeringsrecht induiken. In kwesties van indirecte onteigening, waarin buitenlandse investeerders tegenover een staat komen te staan, pleegt de arbiter zich op de effecten van een overheidsmaatregel te concentreren. Het antwoord op de vraag of er sprake is van indirecte onteigening, hangt uitsluitend af van het 
schadevergoeding, ongeacht de motieven van de overheid. De reden waarom een bepaalde maatregel wordt genomen, bijvoorbeeld ter uitvoering van een wettelijke taak, doet er niet toe. Hoewel de praktijk van de investeringsarbitrage betrekkelijk complex en niet altijd even consistent is, wordt aangenomen dat deze benadering, ook wel 'sole effect'-doctrine genoemd, dominant is (Ortino, 2016: 4-5). Hiertegenover staat de 'police powers'-doctrine, waarbij de nadruk wordt gelegd op de gerechtvaardigdheid van het overheidshandelen uit het oogpunt van behartiging van het algemeen belang. Wanneer de overheid op goede gronden optreedt, kan dat nooit leiden tot indirecte onteigening en de daarmee verband houdende verplichting tot het betalen van een schadevergoeding.

\section{Vergelijking met het Nederlandse bestuursrecht}

Wanneer er geen handelsverdrag met arbitrageclausule is waarop een buitenlandse investeerder zich kan beroepen, dan staat voor hem, zo hij zou willen procederen, alleen de gewone manier van geschillenbeslechting open bij de bestuursrechter. Stel dat een college van $b$ en w strenge voorschriften aan een vergunning heeft verbonden en de betrokkene daartegen in beroep komt omdat zijn winsten onder druk komen te staan, dan is een uitkomst als in de zaak van de kolencentrale Hamburg in Nederland niet goed denkbaar. Een bestuursorgaan mag aan een vergunning voorschriften verbinden als de belangen, die op grond van de bij het besluit te hanteren toetsingskaders moeten worden afgewogen, dat vergen. In welke gevallen een bepaald voorschrift nodig is, staat ter beoordeling van het bestuursorgaan. Daarbij is het bestuursorgaan gehouden tot inachtneming van de algemene beginselen van behoorlijk bestuur. Zo mogen de uit een besluit voortvloeiende lasten bijvoorbeeld niet disproportioneel zwaar zijn, in vergelijking met het effect daarvan op de met het besluit te dienen belangen. Hiervan is geen sprake wanneer een gemeente de bouw van een koeltoren en de aanleg van een vistrap ter bescherming van het aquatisch milieu als voorschriften aan een vergunning verbindt.

Evenmin leidt intrekking van een vergunning zoals in de zaak van het schaliegas in Quebec aan de orde was, eenvoudig tot een schadeveroordeling. Bij verandering van beleidsinzichten mag het bestuursorgaan een vergunning voor de toekomst (ex nunc) intrekken. Dan moet het wel gaan om een situatie waarin de door de intrekking te dienen belangen duidelijk zwaarder wegen dan het belang dat de vergunninghouder heeft bij ongewijzigde voortzetting. Veranderde opvattingen over de gevaren van schaliegas voor mens en omgeving, bijvoorbeeld als gevolg van nieuwe wetenschappelijke inzichten met betrekking tot fracking, kunnen zeker als zware belangen worden beschouwd. Temeer nu de intrekking van de vergunning door de wetgever van Quebec is geregeld. Onder omstandigheden kunnen algemene beginselen van behoorlijk bestuur met zich meebrengen dat een overgangstermijn in acht wordt genomen of een zekere financiële compensatie wordt gegeven. Slechts in geval van onevenredige schade 
rechtsbeginsel is het beginsel van de gelijke verdeling van de publieke lasten, ook wel bekend als 'égalité devant les charges publiques'.

Binnen het normale maatschappelijk risico of het normale ondernemersrisico vallende schade komt niet voor vergoeding in aanmerking. Aan het deelnemen aan de maatschappij is inherent dat rekening moet worden gehouden met overheidsmaatregelen die kunnen leiden tot een herschikking van rechten en plichten. De overheid mag haar beleid te allen tijde wijzigen mits zij zorgvuldig met de belangen van betrokkenen omgaat, bijvoorbeeld door bij intrekking van een vergunning betrokkenen de tijd te gunnen om zich op de nieuwe situatie in te stellen. Alleen wanneer het om onevenredige, buiten het maatschappelijk risico vallende en op een beperkte groep personen of bedrijven drukkende schade gaat, is de overheid gehouden tot compensatie. Daarvan is in ieder geval geen sprake bij risicoaanvaarding, die zich voordoet wanneer een bepaalde maatregel voor een redelijk denkend en handelend persoon redelijkerwijs voorzienbaar was en hij er ten tijde van zijn investering rekening mee kon houden. De gedupeerde die verzuimd heeft om rekening te houden met het intreden van een bepaald risico, moet de schade die hij lijdt zelf dragen. Ook meer algemeen komt schade ten gevolge van een schadeoorzaak die redelijkerwijs voorzienbaar was, niet voor vergoeding in aanmerking. Het is de vraag of bij een zo omstreden onderwerp als schaliegasboringen de vergunninghouder op het rustige bezit ervan redelijkerwijs mocht vertrouwen. Waarschijnlijk niet.

\section{Conclusies}

Hoewel staten partij zijn bij de verdragen en alleen staten door een buitenlandse investeerder formeel aansprakelijk kunnen worden gesteld, hebben de verdragen in werkelijkheid een ruimer bereik en strekken zij zich ook uit over de handel en wandel van decentrale overheden. Zou TTIP ongewijzigd worden doorgevoerd, dan laten vergelijkbare verdragspraktijken zien dat gemeenten risico's lopen wanneer zij met buitenlandse investeerders te maken krijgen bij het uitoefenen van bestuursrechtelijke bevoegdheden. De kans dat gemeenten met deze bedrijven in aanraking komen, is groot. Gemeenten hebben op veel beleidsterreinen het eerste juridische contact met justitiabelen. Zij lopen risico's omdat het verre van zeker is waartoe de investeringsarbitrage zal leiden. De hegemonie van de 'sole effect'-doctrine, met alle gevolgen voor het algemeen belang van dien, doet het ergste vermoeden. Met een ongewijzigd TTIP zal bovendien aan internationaal opererende bedrijven de mogelijkheid worden gegeven om de nationale rechtsgang te omzeilen. Deze bedrijven zullen zeker aan forum shopping doen om het meest gunstige resultaat te behalen. Kijk maar naar Vattenfall, die de voor het bedrijf ongunstige uitspraak van de Duitse bestuursrechter liet voor wat het was en alsnog gebruikmaakte van ISDS, met een veel gunstiger afloop. In een dergelijke situatie is niet alleen sprake van bevoorrechting van de buitenlandse investeerder ten opzichte van zijn binnenlandse concurrent. Het poneren van arbitrage naast 
uitvoerende en wetgevende macht in een staatsrechtelijk equilibrium houdt. Zo beschouwd strekken de gevolgen van TTIP ver, té ver.

\section{Literatuur}

Council of European Municipalities and Regions, Position paper on the ongoing negotiations on TTIP: 2015. Gevonden op:

http://www.ccre.org.

Horbach, N., R. Lefeber \& O. Ribbelink, Handboek internationaal recht, Den Haag: 2007.

Italaw, Comprehensive and free database on investment treaties, international investment law and investor-state arbitration. Gevonden op: www.italaw.com.

Meuwese, A.C.M., 'TTIP. Risico én kans voor Europa', Ars Aequi, 2016/2, p. 76-79.

Newcombe, A. \& L. Paradell, Law and practice of investment treaties. Standards of treatment, Alphen aan den Rijn: 2009.

Ortino, F., Defining indirect expropriation. The TTIP approach and the (elusive) search for greater certainty, King's College London Dickson Poon School of Law, Legal studies research paper series, Londen: 2016.

Tietje, C. \& F. Baetens, The impact of Investor-State-Dispute-Settlement (ISDS) in the transatlantic trade and investment partnership, Den Haag: 2014. Gevonden op:

www.rijksoverheid.nl/documenten/rapporten/2014 .

VNG, Factsheet TTIP en gemeenten, 2015. Gevonden op:

https://vng.nl/files/vng/publicaties/2015/ttip-engemeenten_20150715.pdf.

\section{Noten}

1 Zie www.milieudefensie.nl.

2 Zie voor een Europees overzicht: www.ttip-free-zones.eu.

3 Zie www.ttip-leaks.org.

\section{Zie}

http://trade.ec.europa.eu/doclib/docs/2015/november/tradoc_153955.pdf.

5 Zie http://unctad.org/en/PublicationsLibrar.

(C) Boom bestuurskunde 

meer informatie klik hier. 